\title{
LETTERS
}

\section{Urgent care access: finding solutions that match causation}

The recent research article by Mclsaac and colleagues ${ }^{1}$ has generated some important discussions and reflections within our perioperative and quality teams, some of which we would like to share with the readership.

First and foremost, although press coverage may vary with regard to highlighting various parts of the article, we want to emphasize the primary message: the importance of timely access to urgent care, as well as the challenges of providing that care in the face of constrained resources. As clinicians providing that care, it is our responsibility to remain engaged at all levels to look for credible and sustainable solutions.

This brings us to some of the limitations of the findings of the study. As stated in the study, data were collected from 2012 to 2014, during implementation of a new system for categorizing urgent surgeries. Hence, one has to ask:
Was there a "learning curve" in the implementation and execution of this system, which inevitably could have affected access? Could this have influenced the incidence of delays over various time periods of the study period? Because most cases were of the "E" category (i.e., wait time standard of less than 24 hours), does the impact of a delay have the same importance (i.e., mortality and/or morbidity) for the various categories of urgent booking? Finally, do we fully understand which measures could have the greatest impact on minimizing mortality/morbidity as a function of cause of delay? In other words, if, for example, the incidence of "bumping of cases" were decreased by half, would that have the desired effect (i.e., decreasing mortality/morbidity)? Could this be done without increasing resources but by improving communication between the various stakeholders?

In conclusion, this study has generated important discussions with the various stakeholders within our institution, and we encourage other institutions to have these conversations, as we constantly strive toward more patientcentred solutions.

\section{Paul E. Beaule MD}

Professor of Surgery, University of

Ottawa, Ottawa, Ont.

\section{Sudhir Nagpal MD}

Division Head, Department of Surgery, University of Ottawa, Ottawa, Ont.

\section{Fady Balaa MD}

Head, Division of General Surgery, University of Ottawa, Ottawa, Ont.

\section{Sudhir Sundaresan MD}

Professor of Surgery and Division Head of Thoracic Surgery, The Ottawa Hospital, Ottawa, Ont.

Cite as: CMAJ 2018 January 15;190:E56. doi: $10.1503 / \mathrm{cmaj} .733536$

\section{Reference}

1. Mclsaac DI, Abdulla K, Yang H, et al. Association of delay of urgent or emergency surgery with mortality and use of health care resources: a propensity score-matched observational cohort study. CMAJ 2017;189:E905-12.

Competing interests: None declared. 